\title{
Aa. Vv., Barbey polémiste, «Littératures», n. 58/59
}

\section{Maria Emanuela Raffi}

\section{(2) OpenEdition}

\section{Journals}

\section{Edizione digitale}

URL: http://journals.openedition.org/studifrancesi/8018

DOI: 10.4000/studifrancesi.8018

ISSN: 2421-5856

\section{Editore}

Rosenberg \& Sellier

\section{Edizione cartacea}

Data di pubblicazione: 1 juillet 2009

Paginazione: 426-427

ISSN: 0039-2944

\section{Notizia bibliografica digitale}

Maria Emanuela Raffi, «Aa. Vv., Barbey polémiste, «Littératures», n. 58/59», Studi Francesi [Online], 158 (LIII | II) | 2009, online dal 30 novembre 2015, consultato il 11 janvier 2021. URL: http://

journals.openedition.org/studifrancesi/8018; DOI: https://doi.org/10.4000/studifrancesi.8018

Questo documento è stato generato automaticamente il 11 janvier 2021.

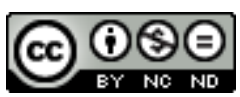

Studi Francesi è distribuita con Licenza Creative Commons Attribuzione - Non commerciale - Non opere derivate 4.0 Internazionale. 


\title{
Aa. Vv., Barbey polémiste, «Littératures», n. 58/59
}

\author{
Maria Emanuela Raffi
}

\section{NOTIZIA}

Barbey polémiste, «Littératures», n. 58/59, 2008, pp. 433.

1 Nel numero monografico dedicato da «Littératures» a Barbey polémiste, curato da Pierre GLAUDES e Marie-Catherine HUET-BRICHARD, la prima sezione di studi è dedicata alle relazioni, più o meno polemiche, dell'autore con altri autori o aspetti della letteratura contemporanea. Dal violento attacco al 'mostro sacro' Victor Hugo del 1862 (La polémique et ses paradoxes: Barbey et "Les Misérables". De l'exercice de la mauvaise foi) presentato da M.-C. HUET-BRICHARD, ai due studi su Tocqueville in aperta polemica sulla «question révolutionnaire» (Barbey face à Tocqueville di Francesco SPANDRI), alla critica misogina e feroce contro George Sand, “plagiaire du génie masculin qu'elle pille sans vergogne non sans l'affadir et l'affaiblir" (Jules et George: le dessous d'une animosité) analizzata da Mathilde BERTRAND, si passa alle critiche polemiche nei confronti di rappresentanti significativi delle letterature straniere (Gloires littéraires mises à nu. Barbey d'Aurevilly critique de Goethe et d'E.T.A.Hoffmann, de Dante et de Leopardi di Helmut METER), per arrivare all'invettiva e al sarcasmo nei confronti di un intero genere letterario poco apprezzato da Barbey, il teatro (Barbey d'Aurevilly et le théâtre: discours critique, discours polémique di P. ALEXANDRE-BERGUES), e concludere infine la sezione con uno sguardo d'insieme, curato da M.-F. MELMOUX-MONTAUBIN sulla polemica di Barbey contro i giornali, accusati di decadenza e di parzialità (Grandeur et décadence de la presse au XIX ${ }^{e}$ siècle selon Jules Barbey d'Aurevilly).

2 Gli studi raggruppati nella seconda parte («Imaginaire, esthétique et rhétorique de la polémique») indagano i modi di espressione e i contenuti della polemica aurevilliana, a partire dall'indagine di caroline SIDI sulle "figures obsédantes" dell'immaginario di Barbey che costituiscono una sorta di galassia della "sombre énergie" e della "force 
sauvage" il cui modello primo è il mondo medievale (L'imaginaire du combat dans la Critique aurevillienne). In Polémique et fantaisie dans l'œuvre critique de Barbey d'Aurevilly, cécile RUMEAU mostra come la «fantaisie» passi dal ruolo di «cible» nei primi scritti critici di Barbey, fortemente ostili alla «Bohème» in nome dell'autorità, ad un ruolo attivo all'interno della polemica stessa e alla natura variabile, «umorale» e spesso eccessiva della critica aurevilliana. Un apporto in controtendenza è rappresentato dallo studio di Frédérique MARRO, La bonhomie dans l'œeuvre critique de Barbey d'Aurevilly, in cui è messa in luce "la bonhomie dans toutes ses nuances" della scrittura critica di Barbey: giovialità ed entusiasmo di "une écriture espiègle et spontanée", che coltiva il gusto della facezia "spirituelle et bouffonne" e cerca di prendere le distanze dalla volgarità contemporanea. Il gusto e la capacità di Barbey di realizzare una conversazione ricca e vivace sono sottolineati anche nell'articolo di Marie-Christine NATTA, Politesse et polémique: la conversation de Barbey d'Aurevilly, definito "très brillant causeur", mentre Catherine MAYAUX indaga il suo uso della citazione "instrument privilégié de la critique aurevillienne" in quanto strumento di manipolazione dell'autore citato e del lettore; elemento a volte polemico, a volte semplice nutrimento e arricchimento della lingua (Références et citations littéraires comme instruments polémiques dans l'œuvre critique de Barbey d'Aurevilly). Dominique MILLET-GÉRARD sposta l'analisi sul piano dei contenuti della polemica aurevilliana, prendendo in esame in Le bestiaire aurevillien la galleria di ritratti ironici di contemporanei fornita dagli scritti critici di Barbey: Proudhon "énorme grenouille en lunettes", Sainte-Beuve "friand chat littéraire", Renan "un reptile et non pas un aigle", etc., la cui fonte principale è da ritrovare in La Fontaine.

3 I rapporti della scrittura polemica con i generi della "fiction" sono l'oggetto della terza sezione («Écriture polémique et fiction»), che inizia con la separazione sottolineata da Josette soutet fra la critica e il romanzo: Du roman à la critique: l'exemple de l'histoire. Partendo dalla grande dignità attribuita da Barbey allo storico (e quindi al critico che si fonda sulla storia), lo studio ripercorre il ritratto ideale che Barbey ne fornisce e che dovrebbe riunire due qualità quasi contraddittorie: "l'impartialité du scientifique [...] et la partialité du juge surnaturellement informé". In Polémique des descriptions dans l'écriture critique et romanesque, Alice DE GEORGES MÉTRAL chiarisce la prossimità e la distanza della scrittura di Barbey dal realismo e dal naturalismo. Il discrimine è dato soprattutto dalla descrizione, che nella visione aurevilliana tende da una parte alla "spiritualisation de la matière" e traduce contemporaneamente una stretta correlazione fra ritratto individuale e situazione della società. Ad una opera particolare, Un prêtre marié, appare legato lo studio di Lydie PARISSE, dedicato alla figura della visionaria protagonista dell'inquietante romanzo di Barbey, esempio di un "fantastique théologique" costruito su "mises en scène spectaculaires" e su una "idéologie pénitentielle" (Le phénomène visionnaire dans "Un prêtre marié". La perte de soi comme arme polémique), mentre in Barbey et la parabole Pierre GLAUDES descrive il tentativo operato dai racconti di Barbey di «tracer une voie d'accès au divin, en révélant la présence au cœur du réel d'une puissance obscure passant les limites de l'humain». Poste alla fine di un percorso che va da Chateaubriand, a Vigny, a Balzac, Les Diaboliques hanno un'organizzazione narrativa che ricorda la parabola in quanto "récits exemplaires", portatori di un "dispositif herméneutique global" per ciascuna storia. La polémique au divan: un parallèle entre la violence romanesque et l'éreintement critique, ultimo contributo su Barbey, stabilisce delle importanti corrispondenze tra la violenza polemica espressa da Barbey nella scrittura critica e quella della fiction narrativa: 
"l'éreintement manipule des angoisses qui fondent son univers romanesque" - scrive Laurence CLAUDE-PHALIPPOU - ma "l'éreintement" del critico si nutre alla stessa fonte, utilizza ed esprime le stesse ossessioni. 